\title{
BMJ Open Quality Applying local context to design and implement patient room whiteboards
}

\author{
Carleene Bañez (D) , ${ }^{1}$ Stefano Gelmi, ${ }^{1}$ Nikki Bansil, ${ }^{2}$ Rachel Drebit, ${ }^{3}$ \\ Shirley Solomon, ${ }^{4}$ Jennifer Yoon, ${ }^{5}$ Vanessa Burkoski, ${ }^{6}$ Barbara Collins, ${ }^{7}$ Trevor Hall ${ }^{8}$
}

To cite: Bañez C, Gelmi S, Bansil N, et al. Applying local context to design and implement patient room whiteboards. BMJ Open Quality 2021;10:e00907. doi:10.1136/ bmjoq-2019-000907

Received 27 December 2019 Revised 27 October 2020 Accepted 17 December 2020

Check for updates

(c) Author(s) (or their employer(s)) 2021. Re-use permitted under CC BY-NC. No commercial re-use. See rights and permissions. Published by BMJ.

${ }^{1}$ Healthcare Safety and Risk Management, Healthcare Insurance Reciprocal of Canada, Toronto, Ontario, Canada

${ }^{2}$ Quality and Patient Safety, Humber River Hospital, Toronto, Ontario, Canada

${ }^{3}$ Simulation Program Corporate Education, St Michael's Hospital, Toronto, Ontario, Canada

${ }^{4}$ Research, Quality and Patient Safety, Humber River Hospital, Toronto, Ontario, Canada

${ }^{5}$ Professional Practice, Quality and Patient Safety, Humber

River Hospital, Toronto, Ontario,

Canada

${ }^{6}$ Chief Nursing Executive,

Humber River Hospital, Toronto, Ontario, Canada

${ }^{7}$ President and CEO, Humber River Hospital, Toronto, Ontario, Canada

${ }^{8}$ Vice President, Healthcare Safety and Risk Management, Healthcare Insurance Reciprocal of Canada, Toronto, Ontario, Canada

Correspondence to

Carleene Bañez;

carleene.banez@gmail.com

\section{BACKGROUND}

Within hospital environments, whiteboards have become tools to facilitate communication, coordinate patient care, and engage patients. ${ }^{12}$ Humber River Hospital, a large community hospital in Toronto Canada, moved into a new building with blank wallmounted dry-erase whiteboards in each inpatient room. Although whiteboards were made available in these rooms, there was no standard practice in place to guide how information should be shared with patients and families using the whiteboards or how often this information should be updated.

\section{AIM}

The aim of this study was to design a standardised whiteboard using human factors methods, such as semi-structured interviews, user-centred design, and usability testing to improve provider-patient communication.

\section{METHODS}

Between November 2017 and May 2018, a user-centred design process, an approach informed by the needs and understanding of a specific end-user group, ${ }^{3}$ was used to evaluate existing whiteboard utilisation, determine what information to standardise, and to create a single design to be implemented across inpatient units.

A human factors specialist conducted pre-implementation semi-structured interviews to assess pre-existing whiteboard utilisation. Semi-structured interviews with unit managers and clinical practice leaders $(n=10)$, and nurses $(n=46)$ were conducted to determine what information these healthcare providers found important to share with patients. With their consent, semi-structured interviews were conducted with patients and families $(n=33)$ which confirmed that clinician recommendations aligned with the patients' and families' perspectives. Input from these three groups identified the need for customised whiteboard content for the following six clinical areas: Inpatient Medicine and Surgery Units (figure 1), ${ }^{4}$ Intensive Care Unit (ICU), Birthing Unit, Mother and Baby Unit, Neonatal ICU and Children's Inpatient Unit. Common elements were standardised across all six designs, including the care team, date, room number and questions/comments. Customised information was needed to accommodate the patient population in the Maternal and Child clinical areas and the ICU. For example, in the Birthing Unit and Mother and Baby Unit, both mother and baby receive care. As such, the whiteboards were customised with dedicated care sections for both patients.

An iterative approach was used to develop the visual designs for each clinical area. The layout, fonts and font sizes, and other design elements were modified several times based on feedback from the clinical areas. A total of 13 design iterations were used until the final designs were identified. Heuristic principles, a guideline to ensure intuitive product design, ${ }^{5}$ was used to guide the whiteboard designs. In May 2018, six whiteboard designs were implemented on the inpatient units.

Three months post-implementation, a second set of patients and families $(n=10)$ were asked to provide feedback through semi-structured interviews regarding their experience using the newly implemented whiteboards. This small evaluation was used to understand if patients and families noticed that information was being communicated through the whiteboards. Six months post-implementation, a usability test was conducted with 35 nurses, five nurses from each inpatient area, to assess how well the new whiteboards supported nurses in effectively communicating with patients. The usability test was conducted individually where each nurse was presented with patient scenarios. The scenarios consisted of two representative patients typical of their inpatient area. The usability test administrator provided clinical 


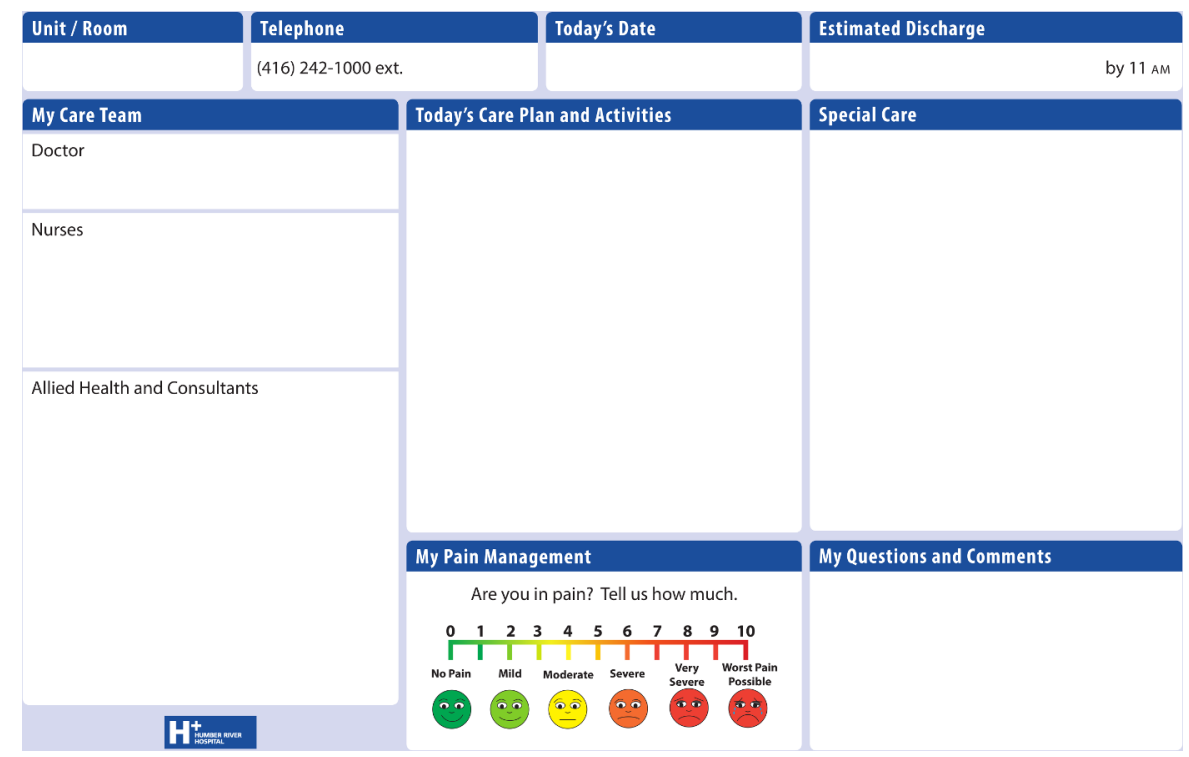

Figure 1 Whiteboard design implemented on inpatient medicine and surgery units.

details for each patient and the nurse wrote information on the whiteboard they felt would be important to communicate to the patient and their family. After each scenario, the nurse was asked to indicate if the sections on the whiteboard aligned with how they thought patientrelated information should be organised to communicate effectively with patients.

Patients or the public were not involved in the design, or conduct, or reporting, or dissemination plans of our research.

\section{RESULTS}

The results of post-implementation interviews indicated that $80 \%(n=10)$ of patients and families looked at the whiteboard for information. The most valued pieces of information were the nurses' names and the care plan. The main concern was that whiteboard placement within the inpatient room made it difficult for patients and families to view.

Usability test results showed that most nurses updated the whiteboards with their names and the physician's name, which improves the ability of patients to identify their physicians. ${ }^{6}$ Nurses also updated the date and unit specific details with key patient information (e.g., baby's weight on NICU whiteboards). Pre-implementation, care providers updated the whiteboards intermittently. Postimplementation, updating information on the whiteboards became a task on the patient safety checklist to be updated once a shift. The Canadian Patient Experiences Survey-Inpatient Care (CPES-IC) is a standardised questionnaire that enables patients to provide feedback about the quality of care they received during their inpatient stay in a Canadian acute care hospital. This survey provides a platform for national comparisons and benchmarking to measure patient experience.

As a proxy measure, the following three questions from the CPES-IC survey were evaluated pre-implementation and post-implementation of the new whiteboards. These questions ask patients to provide feedback regarding information being communicated to them about their care:

- \#38, 'Did you receive enough information from hospital staff about what to do if you were worried about your condition or treatment after you left the hospital?'

- \#33, 'During this hospital stay, did you get all the information you needed about your condition and treatment?'

- \#35, 'Were you involved as much as you wanted to be in decisions about your care and treatment?'

Top box results were as follows, for question \#38, the mean increased from $47.1 \%$ to $54.1 \%$, for question \#33, the mean increased from $55.6 \%$ to $58.2 \%$, and for question \#35, the mean increased from $50.7 \%$ to $53.2 \%$ (figure 2). The term 'top box' refers to the percentage of respondents who selected the 'top' or most desired answer. For question \#38, the top box response was 'completely', and for questions \#33 and \#35, the top box response was 'always'. Although these CPES-IC results show a positive change, the difference is minor and may not be significant.

\section{CONCLUSIONS}

From this study, two key findings surfaced: (1) Although the goal was to create a single design for all inpatient units, the study results identified the need for six customised whiteboard designs to align with the needs of each clinical area, specifically the Maternal and Child units and the ICU and (2) The success of whiteboard utilisation is dependent on the placement of the whiteboard in the patient room. Although the optimal location would be to place whiteboards directly in front of the patient bed, this is not always feasible as layouts vary from room to room. 


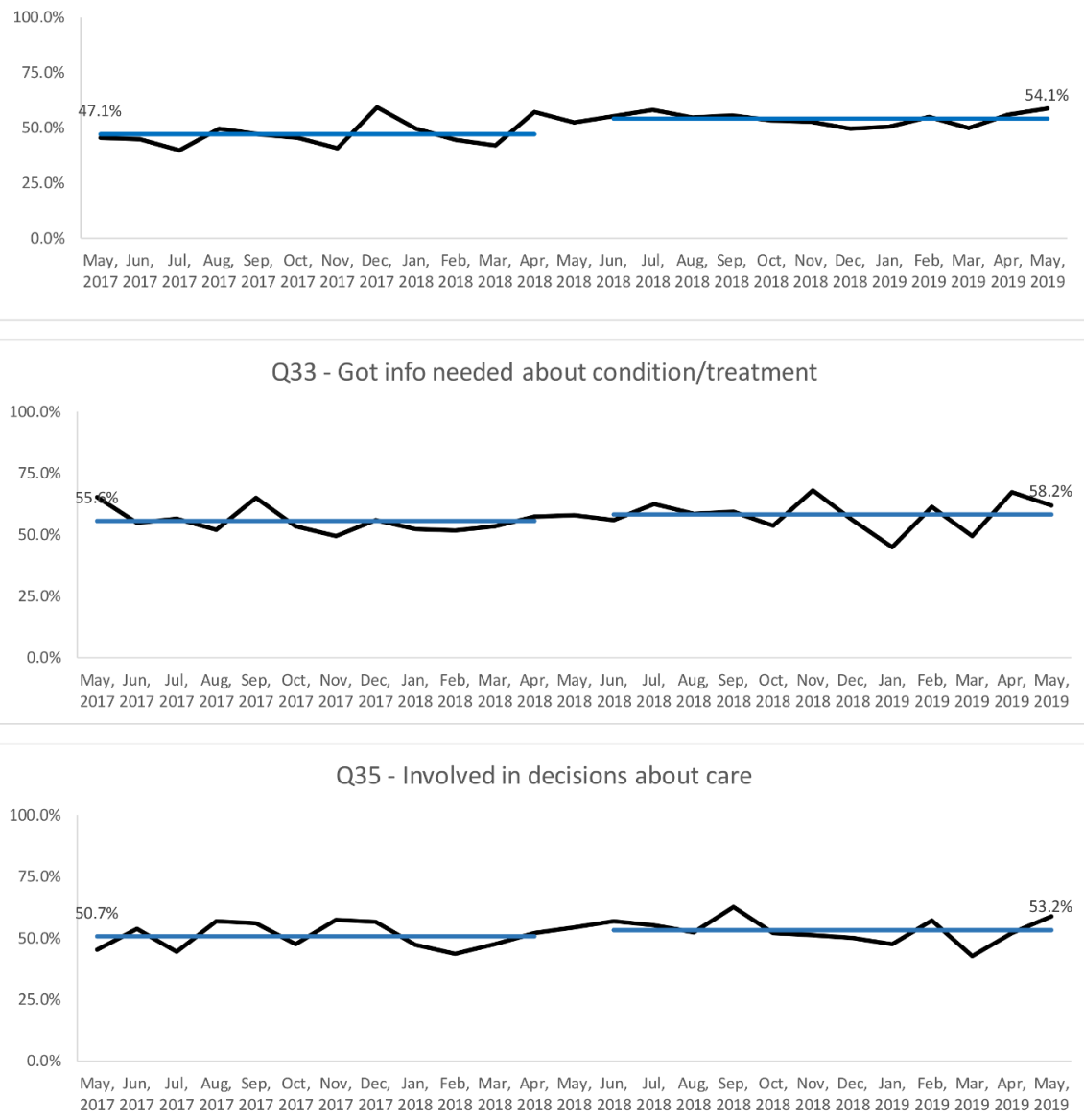

Figure 2 Top box results for CPES-IC survey questions \#38, \#33 and \#35. CPES-IC, Canadian Patient Experiences SurveyInpatient Care.

This study has limitations and it is important to note that as the standardised CPES-IC questions evaluated do not provide specificity, over time, more focused associations will need to be created to target definitive feedback regarding whiteboard designs and placements. Next steps may include assessing the quality of the information written on the whiteboards. This study provides value in demonstrating how local context and applying human factors principles can support the patient experience, and in this example, improve provider-patient communication with an effective whiteboard.

Contributors CB planned the study, collected and interpreted the data, analysed survey results and drafted manuscript. SG collected and interpreted the data, designed the whiteboard and reviewed the manuscript. NB designed the whiteboard and reviewed the manuscript. RD collected data and reviewed the manuscript. SS drafted and reviewed the manuscript. JY, VB and BC reviewed the manuscript. TH contributed to the study design, drafted and reviewed the manuscript.

Funding The authors have not declared a specific grant for this research from any funding agency in the public, commercial or not-for-profit sectors.

Disclaimer As this met the institutional guideline for quality improvement, Research Ethics Board approval was not sought.

Competing interests None declared.

Patient and public involvement Patients and/or the public were not involved in the design, or conduct, or reporting, or dissemination plans of this research.
Patient consent for publication Not required.

Provenance and peer review Not commissioned; externally peer reviewed.

Open access This is an open access article distributed in accordance with the Creative Commons Attribution Non Commercial (CC BY-NC 4.0) license, which permits others to distribute, remix, adapt, build upon this work non-commercially, and license their derivative works on different terms, provided the original work is properly cited, appropriate credit is given, any changes made indicated, and the use is non-commercial. See: http://creativecommons.org/licenses/by-nc/4.0/.

ORCID iD

Carleene Bañez http://orcid.org/0000-0002-5036-2574

\section{REFERENCES}

1 Tariq A, Baysari M, Pedersen C, et al. Examining barriers to healthcare providers' adoption of a hospital-wide electronic patient journey board. Int J Med Inform 2018;114:18-26.

2 Sehgal NL, Green A, Vidyarthi AR, et al. Patient whiteboards as a communication tool in the hospital setting: a survey of practices and recommendations. J Hosp Med 2010;5:234-9.

3 McCurdie T, Taneva S, Casselman M, et al. mHealth consumer Apps: the case for User-Centered design. Biomed Instrum Technol 2012;46:49-56.

4 Garra G, Singer AJ, Domingo A, et al. The Wong-Baker pain faces scale measures pain, not fear. Pediatr Emerg Care 2013;29:17-20.

5 Zhang J, Johnson TR, Patel VL, et al. Using usability heuristics to evaluate patient safety of medical devices. J Biomed Inform 2003;36:23-30.

6 Wahlberg K, Lambirth S, Gardner Z. Improving patients' ability to identify their physicians through the use of physician facecards and whiteboards. BMJ Open Qual 2019;8:e000606. 